\title{
A CRITICAL ANALYSIS OF 'CREATIVITY' IN SUSTAINABLE PRODUCTION AND DESIGN
}

\author{
Thomas EMPSON ${ }^{1}$, Shannon CHANCE $^{2}$ and Shushma PATEL ${ }^{1}$ \\ ${ }^{1}$ Nathu Puri Institute for Engineering and Enterprise, London South Bank University \\ ${ }^{2}$ UCL Centre for Engineering Education \& TU Dublin
}

\begin{abstract}
This paper provides a system level perspective of the contextual pressures facing designers, engineers and businesses today. In it, we challenge negative creative norms and we champion positive 'post normal' creativity to enable a sustainable future. We hypothesise that organisations working towards creative sustainable solutions are driven by a purpose designed to respond to the current and contextual pressures faced by the Earth's systems, a global society and a global economy. Developing motivations within a sustainable system will require instilling a long-term world-view perspective in all learnersand in this we include international leaders and industrialists, business owners, academic teachers and pupils. A regenerative mind-set must be encouraged across the collective of engineers, designers and business leaders - so that humanity can realise ecological, social and financial prosperity. 'Business as normal' must come to an end. We must enable an industrialised humanity to design its way out of unsustainable times. Across undergraduate and postgraduate education, through to Continued Professional Development and lifelong learning, the impact of design and business decisions must be qualified and quantified with respect to the three pillars (people, planet and profit). The consequences must be recognised, discussed, measured and used to productive and healthy advantage. By generating and adopting a more holistic view of impact, we have the potential for making real time measurement in a clean Fourth Industrial Revolution. With tangible measures of impact across full project lifecycle and the full supply and distribution chain, designers and engineers will be better informed to make sustainable decisions.
\end{abstract}

Keywords: Creativity, sustainability, design education, generative, SDGs

\section{INTRODUCTION - CREATIVITY REQUIRES A CONTEXT}

To assess creativity within design and engineering, the lens that defines creativity must be questioned and, if necessary, redefined. This requires us to question what we want for our future: is the creativity lens traditionally assumed in business that prioritises financial growth and profit margins, still appropriate for meeting the needs of today and tomorrow? Moreover, should businesses even be entitled to focus mostly on economics, without considering the toll of their practices on society and the environment? If the context of business was only purely financial then financial growth and design flare alone might be acceptable measures of creativity - with negative consequences seen as just unfortunate, but necessary - but businesses are not silos. They operate within social and environmental contexts; they have a responsibility. Businesses that have a solely financial purpose will develop an 'Architecture of Ownership' [1] that prioritises profits for shareholders; they will develop strategies to achieve their financial ends without considering the larger good. Businesses, engineers, and designers who fail to strike a sustainable balance should no longer, we argue, be acknowledged as 'creative' nor celebrated with awards. If, within the context of product engineering today, environmental and social sustainability do matter, then the creativity of design outcomes should be judged primarily on their advancement towards, and achievement of, holistically sustainable solutions. This paper posits that a new context is emerging wherein product design engineers and businesses must acknowledge their impacts more holistically. Graduate product designers must be capable of well-rounded, iterative decision-making that considers environmental and social sustainability as well as financial. Exploring these issues, we consider what is creative within business today and articulate what types of creativity are needed from designers, engineers and engineering firms. In stating our position, we encourage you, the reader, to 
define what goals and values should govern the business of engineering and product design (EPD) and which of these values should permeate EPD education.

The international vision for development was defined by the United Nations via Sustainable Development Goals (SDGs), set out in 2015 to be achieved by 2030 [2]. This vision implies that - to align with best practices - all firms, including those in EPD, must develop strategies within this context. This drives us to question: Do some engineering firms exceed the UN's 15-year plan by adding value to society that addresses longer-lasting and more complex sustainable development concerns? How and why do these organisations go 'above and beyond' to address the problems humanity faces? Shouldn't they be identified as creative before extractive organisations? How might organisations and researchers learn from creative practices developed within the SDG timeframe to inform ongoing design and engineering practices? We believe the SDGs should help define the context for creativity until 2030. This paper discusses ways academics, industry practitioners and researchers should assess the creativity of business ventures within the context of today's global challenges. Such discussion can help educators understand their role in fostering students to develop long-term world-view perspectives, so that the future workforce is ready and capable. From higher education to lifelong learning, understanding the value of social and ecological development in conjunction with economic development is paramount.

\subsection{Contextualising Creativity through Industrialisation}

Engineering creativity boomed during the First Industrial Revolution, and the purpose governing development was clear: harness the power of nature to generate national and corporate wealth for social advancements and economic gain. This 'normal' approach to business has changed very little from the latter half of the $18^{\text {th }}$ Century to today, but the ramifications of this sense of progress weight heavily on the natural environment and on geographically distanced communities. The population of Earth has continued to grow steadily and implementation of these short-sighted measures of progress has spread. Excessive production, consumption and waste characterise engineering and product design operations today. A cradle-to-grave approach [3], born in the Industrial Revolution, has proliferated and defines many aspects of human life on Earth today. The world's population is projected to reach 9.8 Billion by 2050 [4] and no clear cultural, political or legal shifts are happening at the scale and speed needed to ensure a safe operating space can be maintained for life on Earth [5]. The question 'can we sustain our current occupation of Earth using current practices?' has been answered definitively as: 'No, we cannot'. Volumes of scientific data and predictions from anthropologists show the industrialisation of Earth has pushed the planet's ecosystems towards a 'tipping point'. Persistence of human life will require a new context. Of paramount importance is identifying how to achieve sustainability; it will require new heights of creativity, and new ways to judge creativity tailored to today's new 'Post normal' times [6].

\subsection{Industrial Revolutions, and how they shape Development and Production}

Rifkin (2011) describes industrial revolutions as being underpinned by innovations in three key areas: energy, travel and communications [7]. For the purpose of this paper, the implication of these three factors on production will be highlighted. The first revolution, beginning in the 1780s in the UK, was enabled by burning coal. It is characterised by steam power, rail transport and a surge in mechanical production including newspapers printed for the masses. The second revolution, dating to the 1870s in Europe, ushered in: electronic power from burning crude oil, automotive transport, and telephone and TV communications. This second revolution saw the emergence of mass-production more broadly. A third revolution beginning in the 1960s in North America, despite being discredited by Rifkin [7] as not as seismic as the first two to warrant revolution status, has been associated with nuclear power, air travel, space exploration and the birth of computers and the internet. Factors combined to enable an era of automated production. Countries leading each industrial revolution simultaneously dominated $\mathrm{CO} 2$ emissions on a time comparison [8], [9]. Unsustainable and pollutive norms were defined in the West, but have been replicated by emerging economies everywhere. Elements to define a fourth revolution are emerging. Using Rifkin's three factors [7], we would need to see green energy usage, along with clean automated transportation and an Internet of Things (IoT) communications network. For these factors to emerge with a circular production system, a new industrial revolution would truly exist. This would provide a new context for creativity, driving a paradigm shift towards sustainable development. But how can education support such a paradigm shift? How can we nurture new thinkers with long-term worldview perspectives able to commercialise a clean future worthy of a Fourth Industrial Revolution status? 


\subsection{Measuring Creativity}

Three academic frameworks are being analysed within this scoping paper. Creativity that is 'contextual, collaborative and complex' (Montuori, 2011) [6] is considered firstly through a 'three pillars of sustainability' lens encompassing 1) People, 2) Planet and 3) Profit [10]. Secondly, the importance of measuring the socio-cultural impact of creative ventures [11] is discussed alongside measuring ecological impact. Thirdly, the need for engineers, designers and enterprises to have long-term worldview 'human perspective' [12] in order to create appropriate solutions is critiqued.

\section{SUSTAINABILITY WITHIN BUSINESS}

The three pillars of sustainability are defined as: People, Planet and Profit [10]. Sustainable development leaders state that a balance between people, the planet and profit must be struck. We, the authors of this paper, agree with these sustainable development ideals and argue that for businesses to be perceived, recognised or awarded for being creative, they need to find sustainable solutions within all three pillars. The out-dated status quo approach celebrates profit and design flare above all else, yielding unsustainable products that can no longer warrant recognition as 'creative'.

\subsection{The Three Pillars of Sustainability}

Each pillar will be discussed, providing an overview of academic frameworks and international policies.

\subsubsection{Pillar One - Planet}

Rockstörm et al (2009) present the nine 'planetary boundaries' theory [13]. In it, they identify a set of nine natural/ecological systems supporting life on Earth. Living within these planetary boundaries provides an environment where humanity 'can continue to develop and thrive' for generations to come (p. 737) [14]. Sadly, four of these nine boundaries are at risk due to humanity's industrialisation of Earth. Currently, large corporate organisations operate primarily to generate capital gain. They have a monopoly over finite natural resources, and with production and consumption patterns becoming increasingly globalised, driven by 'extractive' Western and now global norms, the capitalist system has over stressed Earth's natural ecosystems and put continued life under threat. Shockingly few businesses are developing strategies to omit negative impact towards these life-preserving boundaries, or to undo the previous damage caused. The Ozone Layer is one of the boundaries. An example of international policy to address a planetary boundary is the 1987 Montreal Protocol, signed by 197 nations [15], which called for a ban on toxic substances that were depleting the Ozone Layer. By 2016 the Ozone Layer was showing signs of recovery based on the collective actions taken by these 197 nations to reduce harmful industrial practices [16]. This protocol became a necessary pressure on creativity for non-harmful alternatives to emerge. Table 1 shows how industrial practices affect each of the planetary boundary.

Table 1. Planetary Boundaries and level of threat from industrial activity. Adapted from [14]

\begin{tabular}{|c|c|c|c|}
\hline $\begin{array}{l}\text { Planetary } \\
\text { Boundary }\end{array}$ & $\begin{array}{l}\text { Industrial } \\
\text { Causes }\end{array}$ & $\begin{array}{l}\text { Ecological } \\
\text { Impact }\end{array}$ & $\begin{array}{l}\text { Threat } \\
\text { Level }\end{array}$ \\
\hline $\begin{array}{l}\text { Biosphere } \\
\text { Integrity }\end{array}$ & $\begin{array}{c}\text { Demand for food, water, and natural } \\
\text { resources. }\end{array}$ & $\begin{array}{l}\text { Severe biodiversity loss and changes } \\
\text { ecosystems. }\end{array}$ & High Risk \\
\hline $\begin{array}{l}\text { Biochemical } \\
\text { Flows }\end{array}$ & $\begin{array}{l}\text { Pollutant gases, land-use change, } \\
\text { aerosols. }\end{array}$ & $\begin{array}{l}\text { Damaging living organisms and patterns in } \\
\text { atmospheric circulation. }\end{array}$ & High Risk \\
\hline $\begin{array}{l}\text { Land-System } \\
\text { Change }\end{array}$ & $\begin{array}{l}\text { Converting forests, grasslands, } \\
\text { wetlands into agricultural land. }\end{array}$ & $\begin{array}{l}\text { Reductions in biodiversity, impacts on water } \\
\text { flows and biogeochemical cycling of carbon. }\end{array}$ & $\begin{array}{l}\text { Increasing } \\
\text { Risk }\end{array}$ \\
\hline Climate Change & Deforestation, carbon (CO2). & $\begin{array}{c}\text { Melting icecaps, rising sea levels, climate } \\
\text { change. }\end{array}$ & $\begin{array}{l}\text { Increasing } \\
\text { Risk }\end{array}$ \\
\hline Novel Entities & $\begin{array}{c}\text { Toxic emissions, synthetic, metal and } \\
\text { radioactive. }\end{array}$ & Irreversible effects on living organisms. & $\begin{array}{c}\text { Not yet } \\
\text { Quantified }\end{array}$ \\
\hline $\begin{array}{c}\text { Atmospheric } \\
\text { Aerosol Loading }\end{array}$ & Fertilizer from food industry. & $\begin{array}{l}\text { Pollutes waterways, coastal zones and } \\
\text { terrestrial biosphere. }\end{array}$ & $\begin{array}{c}\text { Not yet } \\
\text { Quantified }\end{array}$ \\
\hline $\begin{array}{c}\text { Ocean } \\
\text { Acidification }\end{array}$ & $\begin{array}{c}\text { A quarter of Industrial CO2 ends up in } \\
\text { the ocean. }\end{array}$ & $\begin{array}{l}\text { Reduced pH levels in sea, reduced fish stock, } \\
\text { shift dynamics of oceans ecosystem. }\end{array}$ & $\begin{array}{l}\text { Safe for } \\
\text { Now }\end{array}$ \\
\hline $\begin{array}{c}\text { Stratospheric } \\
\text { Ozone Depletion }\end{array}$ & $\begin{array}{c}\text { Increased concentrations of } \\
\text { anthropogenic ozone-depleting } \\
\text { chemical substances }\end{array}$ & $\begin{array}{l}\text { Damage to humans, terrestrial and marine } \\
\text { biological systems. }\end{array}$ & $\begin{array}{l}\text { Safe for } \\
\text { Now }\end{array}$ \\
\hline Freshwater Use & Altering natural hydrological systems. & Water-stressed communities and biodiversity. & $\begin{array}{l}\text { Safe for } \\
\text { Now }\end{array}$ \\
\hline
\end{tabular}


The 'Planet' pillar also relates to four of the Sustainable Development Goals: 6, 13, 14 and 15 (see Table 2). UNESCO has identified important mid-term goals for industrial development to be targeted from now until 2030. However, overall, the SDGs can be considered a short-term plan in relation to the last 250 years of the industrialisation of Earth. If new visions are developed every 15 years, the average UK citizen will see five global visions in their lifetime. But over time, we posit, the planetary boundaries must be seen as more important than the SDGs, based on their significance to life and long-term standing. Nevertheless, the SDGs provide an invaluable learning opportunity to set and meet targets and evolve towards a sustainable existence. Learning must distil down from an international partnership level through industrial sectors, learning organisations and academic institutions. Knowledge must be generated and shared for today's learners to be prepared to implement and lead sustainable change. EPD students must learn to associate creativity with sustainability. Helping them understand sustainability by exposing them to the SDGs and design new creations that honour the planetary boundaries is crucial.

Table 2. SDGs grouped based on Biosphere, Social or Economic alliance. Adapted from [16]

\begin{tabular}{|c|c|c|}
\hline SDG & Sustainable Development Goals & Biosphere/Social/Economic \\
\hline SDG 1 & No Poverty & Society (People) \\
\hline SDG 2 & Zero Hunger & Society (People) \\
\hline SDG 3 & Good Health and Well-Being & Society (People) \\
\hline SDG 4 & Quality Education & Society (People) \\
\hline SDG 5 & Gender Equality & Society (People) \\
\hline SDG 6 & Clean Water and Sanitation & Biosphere (Planet) \\
\hline SDG 7 & Affordable and Clean Energy & Society (People) \\
\hline SDG 8 & Decent Work and Economic Growth & Economy (Profit) \\
\hline SDG 9 & Industry, Innovation \& Infrastructure & Economy (Profit) \\
\hline SDG 10 & Reduce inequalities & Economy (Profit) \\
\hline SDG 11 & Sustainable Cities and Communities & Society (People) \\
\hline SDG 12 & Responsible Consumption \& Production & Economy (Profit) \\
\hline SDG 13 & Climate Action & Biosphere (Planet) \\
\hline SDG 14 & Life Below Water & Biosphere (Planet) \\
\hline SDG 15 & Life on Land & Biosphere (Planet) \\
\hline SDG 16 & Peace, Justice and Strong Institutions & Society (People) \\
\hline SDG 17 & Partnerships for the Goals & All three factors \\
\hline
\end{tabular}

\subsubsection{Pillar Two-People}

Of the UN's 17 Goals, eight relate to people and society: SDGs 1, 2, 3, 4, 5, 7, 11 and 15 (see Table 2). Each SDG has a set of sub-targets and indicators to measure progress. Against these targets, developed countries, by and large, score much higher. In developed countries, fewer people experience poverty and lack of access to food and water. Inequity is less dire, even though it still exists in developed countries. At the other end of the spectrum, developing countries need international support, co-creation and application of sound strategies to reach their Sustainable Development Goals and targets. Complex international collaborations will be crucial to achieving the UN 2030 vision across all nations. The quintuple helix model-which considers industry, education, government, society and the environment - depicts the complexity of a 'system of systems' that needs consideration locally, regionally, nationally and internationally. Raworth's (2017) Doughnut Economics framework highlights twelve Social Foundations, derived from the SDGs, that are 'internationally agreed minimum standards for human wellbeing' (p. e48) [5]. These foundations represent basic human rights that businesses and national economics must not negatively impact. Respecting and supporting these human rights requires organisations and individual EPD professionals to understand the long-term world-view impact of business decisions. Raworth's framework challenges organisations and individuals to value citizens and planetary boundaries across all economic activities. Society needs more thinkers able to understand and find solutions across complex and quickly changing contexts. The attitudes and skills designers and engineers need in order to develop solutions to complex, contextual problems are of the utmost importance in stabilising a safe and just existence for all. New and better forms of creativity, applied across the next 10-years, are crucial. Graduates of EPD programmes must be able to operate in this context. With more people working toward these goals, product designers can advance minimum standards for human wellbeing, help meet the 2030 SDG timeline and help achieve a sustainable future. 


\subsubsection{Pillar Three - Profit}

Of the SDGs, four centres on the economy: SDGs 8, 9, 10 and 12 (see Table 2). A key inspiration for this paper is SDG12, Responsible Consumption and Production Patterns. For designers and engineers, this SDG encourages systems and processes that do more, or make more, by using fewer virgin materials. Economic theories such as the Circular Economy and Green Economy consider economic models and approaches against the status-quo of extractive business practices. Today, Generative Organisations are emerging, often with the stated purpose of finding balance between people, planet and profit. The success of these organisations will need to be studied and understood to support a wider transition.

\subsection{Making Sustainability the Context of Creativity}

Securing the existence of humanity on Earth is our primary goal. Within this context, EPD businesses and professionals must engineer a new existence — one that works in harmony with the Earth's natural ecosystems. Across EPD, we must work to enhance conditions for all of society, in a way that does not disadvantage communities outside our own. We need to seek a high quality-of-life and economic prosperity for all. This pressures and challenges EPD as a community of professionals to redefine what 'creativity' means today and to acknowledge that it cannot exist without holistic regard for people, and planet as well as profit. Creating new economic systems that support the transition-toward realising true, holistic, long-term sustainability is vital and we in EPD need to be part of creating effective solutions. As such, this paper calls for product design firms and professionals to articulate and agree upon: (a) what is most important when judging creativity across the economy, ecology and society and (b) how value in these three concepts can filter down into the study of individual projects.

\section{MEASURING CREATIVE ENGINEERING}

We propose adoption of a new value system for contextual creativity, ordered with regard to the three pillars of sustainability. If one adopts the perspective that systems supporting life on Earth have the greatest value, based on their significance and long-term standing, the nine planetary boundaries are essential core considerations for creative evaluation. Any company, project, engineer or designer that considers these boundaries and operationalises them in their work is addressing the most complex and contextual level of creativity. Further prioritisation of the boundaries under the highest levels of risk (see Table 1) and scoping creative solutions within those ecological boundaries shows the greatest level of creative intent. At a secondary level of the creative value system are the 12 social foundations. These social foundations are the quality of human life on Earth. The SDGs present an integrated framework of contextual creativity across the three value system levels. This complex network of 17 goals bridges all system levels: Planet, People and Profit. While clear crossover exists amongst the SDGs, the planetary boundaries, the social foundations, and the economy, they are a stepping stone in a long-term world view perspective. They provide the necessary contextual pressure for EPD firms and professionals to be creative from now until 2030 as industry moves towards realising sustainable development. Longerterm world-views could support humanity's evolution towards a generative or even regenerative era. A lower-tier concern is financial. However, it must be noted that achieving financial growth alone is not creative. Out-dated assumptions that profit is a primary indicator of creativity and success must be shed. Next, we propose 'purpose' as an enabler for contextual creativity. We hypothesise that for an organisation to be able to respond to the external pressures outlined in the value system for contextual creativity (discussed here), the organisation must align its purpose to respect and value a similar system. If a group of people, such as an EPD team or organisation, is encouraged to be creative in response to the external pressures across all three pillars, the internal environment naturally encourages and supports effective responses to those ends. This can make the organisation contextually creative. We posit that such creative organisations must not wait for international policy around planetary boundaries or social foundations to emerge (e.g., the 1987 Montreal Protocol), but they must actively respond to emerging environmental and social data and must generate new solutions. They must lead by example and must drive a paradigm shift. Pro-active and 'Generative Organisations' will align their purpose, membership, governance, finance and networks to operationalise sustainability [1]. Furthermore, organisations that cannot become generative should not be counted as contributing towards a Fourth Industrial Revolution.

\section{CONCLUSION}

The internal purpose of an organisation (or individual) must align with external pressures, if it is to be 
considered generative. If an organisation seeks to be sustainable but only achieves economic development and not social development and environmental preservation, it cannot be seen as generative. Across EPD, we cannot continue to award prizes and bestow honours on companies and individuals for contributions to creativity if these contributions are not truly and holistically sustainable. Being creative today must mean being sustainable and seeking to support people and planet as well as seek profit and foster prosperity for all in a long-term world-view perspective. As EPD educators, we must work to adopt - and also to instil in the minds of tomorrow's design engineers - healthy, sustainable, generative and regenerative perspectives. We have written this paper to challenge educators' conceptions of creativity, and their underlying value systems for identifying, labelling and celebrating creativity. We ask you, as EPD educators, to consider altering your own definition of 'creativity' so that holistic sustainability is a crucial, foundational element of creativity - not a bolt on feature of product design. Moreover, we challenge you to frame scenarios where students build knowledge, skills, and values to become effective and creative decision-makers in this holistically sustainable sense.

\section{REFERENCES}

[1] Kelly M. Owning our future: The emerging ownership revolution, 2012 (Berrett-Koehler Publishers, Oakland).

[2] United Nations. Transforming our world: The 2030 agenda for sustainable development, Resolution Adopted by the General Assembly, 2015.

[3] Global Footprint Network. National Footprint Accounts 2018 Public Data Package, 2018. Global Footprint Network. Available: https://www.footprintnetwork.org/licenses/public-data-packagefree-2018/ [Accessed on 2019, 17 May]

[4] United Nations, World population projected to reach 9.8 billion in 2050, and 11.2 billion in 2100 . Available: https://www.un.org/development/desa/en/news/population/world-populationprospects-2017.html [Accessed on 2019, 02 March], (2017) 21 June.

[5] Raworth K. Doughnut economics: seven ways to think like a 21st-century economist, 2017 (Chelsea Green Publishing, Vermont).

[6] Montuori A. Beyond post normal times: The future of creativity and the creativity of the future, Futures, 2011, 43 (2), pp.221-227.

[7] Rifkin J. The third industrial revolution: how lateral power is transforming energy, the economy, and the world, 2011 (Macmillan Press, New York City).

[8] Le Quéré et al. CO2 and other Greenhouse Gas Emissions. Available: https://ourworldindata.org/co2-and-other-greenhouse-gas-emissions, (2017) May.

[9] Wood, J. How each country's share of global CO2 emissions changes over time. Available: https://www.weforum.org/agenda/2019/01/how-each-country-s-share-of-global-co2-emissionschanges-over-time/ [Accessed on 2019, 17 May], (2019) 10 January.

[10] Kaufman J.C. and Beghetto R.A. Beyond Big and Little: The Four C Model of Creativity. Review of General Psychology, 2009 13, (1) pp1-12.

[11] Savitz A. The triple bottom line: how today's best-run companies are achieving economic, social and environmental success-and how you can too, 2013 (John Wiley \& Sons, Ealing).

[12] Meadows, D.H., Meadows, D.H., Randers, J. and Behrens III, W.W., The limits to growth: a report to the club of Rome, 1972. (Universe Book, Connecticut).

[13] Rockström J., Steffen W., Noone K., Persson Å., Chapin III F.S., Lambin E.F., Lenton T.M., Scheffer M., Folke C., Schellnhuber H.J. and Nykvist B. A safe operating space for humanity. Nature, 2009, pp. 261-472.

[14] United Nations. Montreal Protocol on Substances that Deplete the Ozone Layer. Available: https://treaties.un.org/Pages/ViewDetails.aspx?src=IND\&mtdsg_no=XXVII-2a\&chapter=27\&clang=_en [Accessed on 2019, 02 March], (1987) 16 September.

[15] Steffen W., Richardson K., Rockström J., Cornell S.E., Fetzer I., Bennett E.M., Biggs R., Carpenter S.R., De Vries W., De Wit C.A., Folke C. Planetary boundaries: Guiding human development on a changing planet. Science. 2015, pp736.

[16] Solomon S., Ivy D.J., Kinnison D., Mills M.J., Neely R.R. and Schmidt A. Emergence of healing in the Antarctic ozone layer. Science, 2016, p.269-274.

[17] Rockström J. and Sukhdev P. Contributions to Agenda 2030. Available: https://www.stockholmresilience.org/research/research-news/2017-02-28-contributions-toagenda-2030.html [Accessed on 2019, 02 March] (2016). 